\title{
$X X$. The multiple spectra of gases
}

\section{John Trowbridge \& Theodore Wm. Richards}

To cite this article: John Trowbridge \& Theodore Wm. Richards (1897) XX. The multiple spectra of gases, Philosophical Magazine Series 5, 43:261, 135-139, DOI: 10.1080/14786449708620971

To link to this article: http://dx.doi.org/10.1080/14786449708620971

$$
\text { 曲 Published online: } 08 \text { May } 2009 .
$$

Submit your article to this journal $\pi$

LII Article views: 3

Q View related articles $\asymp$ 
had been attracted. Hence, amongst the rays deflected by the magnet there are some endowed with photographic action.

In addition, I tried to investigate how the photographic action inside the tube varies with the variation of the rarefaction.

The result of the experiments proved that such action takes place even when all the conditions that we judge to be ordinarily connected with the production of the kathodic rays are not satisfied.

Beginning with the internal pressure of $3 / 10$ of a millimetre, at which the tube is filled with a white-violet light that ends at the two electrodes, where from time to time little sparks are visible, the photographic action increases at first rapidly with the rarefaction, and then, from $1 / 100$ of a millimetre onwards, much more slowly.

Finally, to eliminate the doubt that the photographic action inside the tube was due to an electric effluvium between the paper and the metallic cylinder* ${ }^{*}$ I surrounded the latter with a thimble of brass-wire gauze connected to a copper wire dipping into the mercury of the pump, which, in its turn, was put in connexion with the groand.

All the films showed on development a darkening of the same order of intensity as that which was produced without the metallic screen, while the shadow of the whole gauze remained well delineated on the film itself.

While these experiments point to facts notewortly in themselves, they lead us to conchude that Röntgen's rays are already existing inside the tube as well as those studied by Lenard. The ones would pass better than the others through the walls. Hence they alone would pass out if the tube were of a somewhat thick glass.

\section{The Multiple Spectra of Gases. $B y$ John Trowbridge and Theodore Wm. Richards $\dagger$.}

$\mathrm{N}$ a recent paper upon the spectra of argon $\ddagger$ we have shown 1 that the two different spectra of this gas are dependent primarily upon the electrical conditions which cause the gas to glow. The continuous discharge of a high-tension accumulator through the gas produces the red spectrum, while the discharge of a condenser, provided that its oscillations are

* This was already sufficiently contradicted by the fact that the impression came out enormously stronger on the face turned towards the kathode.

† Communicated by the Authors.

$\ddagger$ Suprà, p. 77. 
not damped by the resistance of the tube, or other resistance or impedance, produces the blue spectrum.

It became now a matter of great interest to determine whether the same conclusions apply to other gases, a subject which has already been studied in detail by Wüllner and others. The chief differences between our work and the earlier investigations are : first, the use of a high-tension accumulator instead of an electrical machine or Ruhmkorff coil as the sonrce of electricity; and secondly, the introduction of varying ohmic resistance or impedance between the plates of the condenser in order to study the damping of the spark. It is the object of this paper to emphasize anew the importance of the electrical conditions of the circuit, and to call attention once more to the fact that the behaviour of most elementary gases is in every respect similar to that of argon.

With regard to the spectrum of nitrogen, it has been known for a long time that two spectra could be obtained by means of appropriate changes in the density of the gas, as well as by the introduction of the condenser; but not all investigators have put the same interpretation upon their results. So varying are the views that Angström * and Thalén $\dagger$ believed the familiar channelled spectrum to be due to impurities in the gas. Plücker and Hittorf $\ddagger$, Wüllner $\S$ and Salet $\|$ have proved this view to be false, but they had not at hand the constant current of high tension at our disposal, and their nitrogen was obtained from air containing argon, so that a revision of their work promised to be of great interest.

With our Planté battery of ten thousand volts we bave obtained the usual two different spectra of nitrogen by varying suitably the electrical conditions of the discharge. By means of a continuous discharge with no spark-gap or brush-discharge in the circuit throngh nitrogen under varying pressure we always obtained the channelled spectrum. The glow in the capillary tube, as well as the positive and negative light, was of a delicate pink colour under these conditionsa colour not unlike the red glow of argon. When an air-gap, over which the battery discharges in a brush, is introduced into this circuit, the glow becomes more violet in tinge, and

* Pogg. Annalen, cxliv. p. 300.

+ Bull. Soc. Chim. [2] xxv. p. 183.

t Roy. Soc. Proc. xiii. p. 153; Phil. Mag. [4] xxviii. p. 64.

$\$$ Pogg. Ann. cxxxv. p. 497, cxxxvii. p. 337, cxlvii. p. 321, cxlix. p. 103, cliv. p. 149.

II Ann. Chim. Phys. [4] xxviii. p. 52. Hasselberg, Ames, and others have also studied the nitrogen spectra. 
the spectroscope shows that the red bands are relatively much lower in intensity than before. By increasing the size of this air-gap to its utmost limit, the red bands almost, if not wholly, disappear, while the blue and green ones retain their positions. Under these conditions the capillary tube is filled with a pure blue glow, less intense and vivid than that of argon, however.

When the condenser is introduced, the whole appearance of the tube is utterly transformed. The blue colour of the tube at once changes to a rich bluish green, and the channelled spectrum gives place to bright lines, already well known and mapped. This line spectrum corresponds to the blue spectrum of argon. When the oscillations of the condenser-discharge are damped by means of a suitable resistance or self-induetion interposed between the condenser plates, a channelled spectrum reappears; but in this case the glow in the tube is of a bluish-white colour, the positive and negative lights being of a bright yellow. Whether or not this channelled spectrum is, as it seems, exactly like the one obtained by means of a continuous discharge, photographic mensurement will show. This last appearance is probaily the usual one obtained by means of the Ruhmkorff coil, for then the oscillations induced by the primary condenser are damped by the impedance of the secondary coil and the resistance of the tube.

The spectrum of hydrogen is usually supposed to consist of four bright lines:- $-\mathrm{H}$ a 6563.0 (C), H $\beta$ 4861.5 (F), H $\gamma$ $4340.7(\mathrm{G}), \mathrm{H} \delta 4101.9(\mathrm{H})$, as well as several in the extreme violet and ultra-violet*

Other spectra have been observed also; but owing to the partial understanding of the conditions required to produce them, the voluminous literature $\dagger$ upon the subject leaves a confused idea in the mind of the reader. The continuous discharge of a high tension accumulator through hydrogen gas at tensions varying from $0.05 \mathrm{~mm}$. to $3 \mathrm{~mm}$. and more yields a beautiful white glow in the capillary of a Geissler tube, while the strata in the positive and negative light are often alternately pale pink and pale blue. When examined by a spectroscope with a broad slit, the light from this discharge appears to consist of bands similar to that of nitrogen, as well as of bright lines; but when the slit is narrowed every band is resolved into a multitude of sharp lines of varying

* Acmes, Phil. Mag. [5] xxx. p. 48 (1890).

$\dagger$ Angström, Vogel, Lockyer, Fievez, Wiedemann, Higgins, Wuillner, Hnsselberg, Balmer, Grunwald, Villaxi, Schuster, Salet, Smyth, and others, For references see O. Dammer, Anorgan. Chem. i. p. 369 . 
intensities*, among which the four usual hydrogen lines, although present, are by no means specially prominent. A large capacity is required to change this spectrum into the familiar four-line spectrum which is comparable with the blue spectrum of argon. The change is marked by a sharp alteration in the colour of the glow from white to a deep red. In the process, the bluish-green line $(\mathrm{H} \beta)$, as well as the two in the violet, which retain their early position unaltered, becomes nebulous at its edges $\dagger$; while the red H-line remains sharp and clear. The most marked change in the spectrum, however, is the complete obliteration of all the host of other lines covering the whole spectrum ; and the obvious contrast betwee. the oscillatory and non-oscillatory spectra of this gas is quite as striking as in the case of nitrogen, although somewhat different in nature. This four-line deep red glow appears satisfactorily in a tension of gas of about a millimetre-when the tension of the gas is much higher or lower the resistance is increased, the oscillations are damped, and other lines begin to appear. Curiously enough, however, the damping of the oscillatory discharge does not at first replace all the lines which were extinguished by the introduction of the condenser. At first only a sharp line in the yellow and one in the green begin to appear, and gradually others are added as the impedance is increased.

The relation of these conclusions to the varying spectra of hydrogen observed in stars leads to interesting speculations regarding the nature of the electrical and thermal conditions in the photospheres of these bodies $\ddagger$.

Each of the halogens gives two spectra, one with, and one without the condenser. With iodine, if any of the solid itself is present in the tube, the vapour-tension is so soon altered by the heat of the discharge that the oscillatory discharge is damped and the non-oscillatory substituted. Hence the former can be obtained only for a few moments.

A tube of helium made by Professor Ramsay, the kind gift of the Hon. R. J. Strutt, gave a brilliant yellow glow under the influence of the continuous discharge, and a brilliant blue with the condenser discharge; but since the bright helium lines remained in each, and every other important line in the blue spectrum proved to be an argon line, it is evident that the oscillations produced no considerable effect upon the helium.

* Smyth, Pogg. Ann., Beiblätter [2] vii. p. 286. Wüllner observed this spectrum but did not measure the lines.

$\dagger$ E. Villari, Fievez, and Salet.

$\neq$ E. Ebert, Wied. Ann. liii. 1894. 
As Crookes and others have already pointed out, since many gases yield different spectra under the influence of varying electrical conditions, it is evident that the fact of the existence of two well-marked spectra of argon gives not the slightest presumption in favour of the hypothesis that the new gas is a mixture. In order to discover whether argon possesses a dual nature, the gas must be split up in such a way that its components give different spectra under like electrical conditions; then alone would the evidence of the spectroscope be of weight in proving the dissimilarity of the several parts.

The results of this work are thus far only those which were to have been expected from a high tension galvanic battery, reasouing from the work of other investigators with the Toepler-Holtz machine. The battery, however, gives a current so admirably constant and so easily regulated as to its tension, that we hope to be able to use it as a means of determining whether the oscillatory discharge produces its effect simply by increasing the temperature, or because of some inherent property in the manner of the discharge.

It is our intention to extend the investigation by the systematic photographic study of the action of the varying discharge upon all the elementary gases in the purest condition, as well as upon mixtures, under widely varying conditions of temperiture and pressure.

Harvard University, Cambridge, Mass. U.S.

XXI. On the Generality of a New Theorem.

To the Editors of the Philosophical Magazine. GenTlemen, A CORRESPONDENT writing to me on the 14th of propositions in the paper on "Microscopic Vision" in the October number of the Philosophical Magazine, p. 335, viz.:-

However complex the contents of the objective field, and whether it or parts of it be self-luminous or illuminated in any way however special, the light which emanates from it may be resolved into undulations each of which consists of uniform plane waves

(in which mention is made of only one kind of motion, viz. light), may be further generalized into the following :-

"The most general motion of given period within any space may be analysed into trains of" uniform "plane wares." 